\title{
Isolation of Salmonella enterica Serotype Worthington from a Splenic Abscess in a Patient With Chronic Myeloid Leukemia
}

\begin{abstract}
Splenic abscesses are caused by Staphylococcus aureus, Streptococcus and bacteria belonging to the family Enterobacteriaceae. We report a case of splenic abscess caused by an unusual serotype of Salmonella. A 55 year old man was admitted with complaints of fever and abdominal pain. On the basis of clinical findings and laboratory reports, a diagnosis of chronic myeloid leukemia was made. Ultrasonography of the abdomen revealed a single large cystic lesion in the spleen. Percutaneous drainage of the abscess was carried out. Salmonella enterica serotype Worthington was isolated from a pus sample taken from the abscess. The isolate was resistant to ampicillin, gentamicin, cefotaxime, chloramphenicol and tetracycline, and sensitive to amikacin and norfloxacin. Serotype Worthington is an emerging pathogen. This is the first report of isolation of this serotype from a splenic abscess. In seriously ill patients, such infections should be treated with a combination of antibiotics to circumvent problems with multidrug resistance.

Key Words: Chronic myeloid leukemia, Splenic abscess, Worthington.
\end{abstract}

Splenic abscess usually occurs as a consequence of systemic bacteremia due to infective endocarditis or due to secondary infection in a spleen damaged by infarction or trauma [1]. We describe a case of splenic abscess caused by an unusual serotype of Salmonella in a patient suffering from chronic myeloid leukemia.

\section{Patient and Methods}

A 55-year-old male was admitted to the Sassoon General Hospital, Pune, India in April 1998 with chief complaints of fever with chills and abdominal pain during 10 days. The patient also gave a history of fatigability and weight loss. He

Received on 16 October 2001; revised 25 March 2002.

Address for correspondence: Dr. Abhijit M. Bal. 47/A, Ideal Colony. Radheya Apartments, Flat-2, Kothrud, Pune-411038, Maharashtra, India. Telephone- 91-020-5468311

E-mail-balabhijit@rediffmail.com

The Brazilian Journal of Infectious Diseases 2002;6(2):88-90 (C) 2002 by The Brazilian Journal of Infectious Diseases and Contexto Publishing. All rights reserved.

$1413-8670$ was found to be febrile $\left(39^{\circ} \mathrm{C}\right)$. His pulse rate was 98/minute and blood pressure was 106/76 $\mathrm{mm} \mathrm{Hg}$. On systemic examination, an $8-\mathrm{cm}$ palpable splenomegaly was found and there was abdominal tenderness at the left hypochondrium and umbilical regions. There was no hepatomegaly. Cervical and axillary lymph nodes were palpable. The respiratory, cardiovascular and central nervous systems were normal. Laboratory investigations revealed a hemoglobin level of $9 \mathrm{~g} \%$ and an increased total leukocyte count ( 70 X 10\%/liter). The peripheral blood smear revealed $2 \%$ myeloblasts, $4 \%$ promyelocytes, $9 \%$ myelocytes, $9 \%$ metamyelocytes and $12 \%$ band cells, and was suggestive of chronic myeloid leukemia. The reticulocyte count was $4 \%$ and the platelet count was high ( $500 \times 10^{9} /$ liter $)$. Chromosomal studies could not be undertaken due to economic constraints. Blood urea, serum creatinine and serum electrolyte levels were within normal limits. The patient was negative for Hepatitis B virus surface antigen and antibodies to HIV. Ultrasonography of the abdomen revealed a single large $(11 \times 9.4 \mathrm{~cm})$ cystic lesion in the spleen. No abnormality of the liver or gall bladder was found. 
A clinical diagnosis of splenic abscess was made. Percutaneous aspiration of the pus was carried out under ultrasonography guidance. The pus sample was cultured for aerobic and anaerobic bacteria. Aerobic and anaerobic blood cultures were also made on the day of admission and on day 4. Cefotaxime and amikacin were administered in appropriate dosages before the availability of antibiotic susceptibility reports.

The pus sample and blood samples from blood culture bottles were plated on blood agar and on MacConkey agar plates. The aerobic plates were incubated at $37^{\circ} \mathrm{C}$ and inspected for bacterial growth after 24 hours. Anaerobic blood agar plates were inspected on alternate days for a period of 5 days. The isolate was identified on the basis of standard bacteriological techniques [2]. Antibiotic sensitivity of the isolate was determined with the Kirby-Bauer disc diffusion method [3].

\section{Results}

Non-lactose fermenting colonies in pure culture were isolated on the MacConkey agar plates from the aspirated pus and from the blood sample collected at admission. Based on the gram stain, motility and various biochemical reactions, the organism was provisionally identified as Salmonella. The isolate was found to be sensitive to amikacin and norfloxacin and resistant to ampicillin, cefotaxime, gentamicin, chloramphenicol and tetracycline. On the basis of the antibiotic sensitivity report, cefotaxime was omitted and therapy was administered with a combination of amikacin and intravenous norfloxacin. The patient's condition improved clinically and a subsequent ultrasonography of the spleen showed a moderate degree of splenic enlargement, without evidence of residual pus. A blood sample collected on the $4^{\text {th }}$ day after admission did not yield bacterial growth.

The isolates were sent to the National Salmonella and Escherichia Centre, Research and Development Division at the Central Research Institute, Kasauli, India where they were identified as Salmonella enterica serotype Worthington (13,23: z: 1,w).

\section{Discussion}

Splenic abscesses are more likely to occur in individuals with predisposing factors such as sickle cell hemoglobinopathy, endocarditis and HIV infection [4]. In the case that we report here, the patient was suffering from chronic myeloid leukemia. Splenomegaly is a common clinical finding in patients suffering from myeloproliferative disorders and in these patients, splenic infarction is a predisposing factor for the development of splenic abscess [5]. The bacteria that have been most commonly recovered from splenic abscesses include Staphylococcus aureus, Pseudomonas spp., and bacteria belonging to the family Enterobacteriaceae [6]. Approximately 20\% of splenic abscesses are caused by Salmonella; serotype Typhi being most commonly reported [7].

The incidence of human infection due to the nontyphoidal serotypes of Salmonella is on the rise. These include the serotypes, Heidelberg, Newport, Montevideo, Javiana [8] and a recent report of typhoidlike illness due to serotype Kapemba [9]. Serotype Worthington is an emerging pathogen and has been recently reported as a causative agent in outbreaks of neonatal septicaemia and meningitis $[10,11]$. We have earlier reported a case of endocarditis due to this serotype [12]. However, to our knowledge, this is the first report of isolation of this serotype from a splenic abscess.

In our patient, the isolate was obtained not only from the abscess but also from a blood sample collected on the day of admission. Blood cultures have been reported to be positive for bacteria in about $70 \%$ of cases of multiple splenic abscesses and in 14\% of patients with solitary abscesses [4]. The isolate from our patient was found to be resistant to multiple antibiotics, including cefotaxime, and sensitive to amikacin and norfloxacin. In a recent study carried out by investigators from Centers for Disease Control and Prevention, Atlanta, a significant increase in antibiotic resistance has been found amongst the isolates of nontyphoidal Salmonella [8]. Resistance to multiple antibiotics including the third generation cephalosporins has also been reported in isolates of serotype 
Worthington from other clinical specimens, such as CSF [11]. Infection with multi-drug resistant nontyphoidal Salmonellae is associated with high mortality. In the case that we describe, drainage of the abscess and timely application of appropriate therapy, following the availability of antibiotic susceptibility data led to a favorable outcome from this acute episode. Busulfan was contemplated for chronic myeloid leukemia but the patient was discharged against medical advice.

\section{Acknowledgements}

We thank the National Salmonella and Escherichia Centre, Research and Development Division, Central Research Institute, Kasauli, India for serotyping of the isolate and the Dean of the B.J. Medical College, Pune, for providing the necessary facilities at our institute.

\section{References}

1. Ravikumar K.H., Kate V., Ananthakrishnan N., et al. Splenic abscess due to Salmonella infection. Indian Journal of Medical Microbiology 1996;14:109-11.

2. Collee J.G., Miles R.S., Watt B. Tests for identification of bacteria. In: Collee J.G., Fraser A.G., Marmion B.P., Simmons A. (eds): Mackie and McCartney Practical Medical Microbiology, 14 ${ }^{\text {th }}$ edition. Churchill Livingstone, New York, 1996, pp 131-49.

3. Collee J.G., Miles R.S., Watt B. Laboratory control of antimicrobial therapy. In: Collee J.G., Fraser A.G., Marmion B.P., Simmons A. (eds): Mackie and McCartney Practical Medical Microbiology, $14^{\text {th }}$ edition. Churchill Livingstone, New York, 1996, pp 151-78.

4. Levison M.E., Bush L.M. Peritonitis and other intraabdominal infections. In: Mandell G.L., Bennett J.E., Dolin R. (eds): Principles and Practice of Infectious Diseases, $4^{\text {th }}$ edition. Churchill Livingstone, New York, 1995, pp 705-40.

5. Faller D.V. Diseases of lymph nodes and spleen. In: Claude Bennett J., Plum F. (eds): Cecil Textbook of Medicine, $20^{\text {th }}$ edition. WB Saunders Company, Philadelphia, 1996, pp 968-74.

6. Gadacz T., Way L.W., Englebert Dunphy J. Changing clinical spectrum of splenic abscess. Am J Surg 1974; $128: 182-7$.
7. Nelken N., Ignatius J., Skinner M., Christensen N. Changing clinical spectrum of splenic abscess. Am J Surg 1987; 154:27-32.

8. Miller S.I., Hohmann E.L., Pegues D.A. Salmonella (Including Salmonella Typhi). In: Mandell G.L., Bennett J.E., Dolin R. (eds): Principles and Practice of Infectious Diseases, $4^{\text {th }}$ edition. Churchill Livingstone, New York, 1995, pp 2013-33.

9. Sarnighausen H., Benz C., Eickenberg M., et al. Typhoid fever due to Salmonella Kapemba infection in an otherwise healthy middle-aged man. J Clin Microbiol 1999; 37:2381-2.

10. Rodrigues C., Mehta A.P., Bavdekar M., et al. Neonatal outbreak of Salmonella Worthington septicaemia in the city of Mumbai. Bombay Hospital Journal 1997;39:71-3.

11. Udani R.H., Kabra N.S., Nanavati R.N., Baveja S. Outbreak of Salmonella worthington meningitis in neonatal intensive care unit. Indian Pediatr 1999;36:300-3.

12. Ghadage D.P., Bal A.M. Infective endocarditis due to an unusual serotype of Salmonella. Indian Heart J 2001;53:350-1. 